\title{
Peripheral and segmental spinal abnormalities of median and ulnar somatosensory evoked potentials in Hirayama's disease
}

\author{
A Polo, M Curro' Dossi, A Fiaschi, G P Zanette, N Rizzuto
}

See end of article for authors' affiliations

\section{Correspondence to:} Dr Alberto Polo,

Department of Neurology, City Hospital, Piove di Sacco, Padova, Italy; apolo@

asl 14 chioggia.veneto.it

Received 21 June 2002

In revised form

9 December 2002

Accepted

15 January 2003

\begin{abstract}
Objectives: To investigate the origin of juvenile muscle atrophy of the upper limbs (Hirayama's disease, a type of cervical myelopathy of unknown origin).

Subjects: Eight male patients were studied; data from 10 normal men were used as control.

Methods: Median and ulnar nerve somatosensory evoked potentials (SEP) were recorded. Brachial plexus potentials at Erb's point (EP), dorsal horn responses (N13), and subcortical (P14) and cortical potentials (N20) were evaluated. Tibial nerve SEP and motor evoked potentials (MEP) were also recorded from scalp and spinal sites to assess posterior column and pyramidal tract conduction, respectively.

Results: The most important SEP findings were: a very substantial attenuation of both the EP potentials and the N13 spinal responses; normal amplitude of the scalp N20; and normal latency of the individual peaks (EP-N9-N13-P14-N20). Although both nerves were involved, abnormalities in response to median nerve stimulation were more significant than those in response to ulnar nerve stimulation. There was little correlation between the degree of alterations observed and the clinical state. Latencies of both spinal and cortical potentials were normal following tibial nerve stimulation. The mean latency of cervical MEP and the central conduction time from the thenar eminence were slightly but significantly longer in patients than in controls.

Conclusions: The findings support the hypothesis that this disease, which is clinically defined as a focal spinal muscle atrophy of the upper limb, may also involve the sensory system; if traumatic injury caused by stretching plays a role in the pathogenesis, the damage cannot be confined to the anterior horn of the spinal cord.
\end{abstract}

$\mathrm{S}$ pinal muscle atrophy of the distal upper extremities, with juvenile onset and sporadic occurrence (Hirayama's disease), is a rare clinical entity almost exclusively affecting males. Cold paresis and fine postural tremor are common associated symptoms. Since the first report by Hirayama, ${ }^{1}$ about 500 cases have been described, mainly from southeast Asia and Japan, ${ }^{2-6}$ and only rarely from other countries, where the disease may have been underdiagnosed. Electromyographic abnormalities (signs of chronic denervation) have been found mainly in the hand and forearm muscles and in the triceps muscle, and sometimes these abnormalities are also present on testing the contralateral non-affected side or the leg muscles. ${ }^{7-9}$ Nerve conduction studies have provided little evidence of impairment: compound motor action potentials (c-MAP) may be reduced in amplitude when recordings are obtained from the affected muscles, and a slight slowing of conduction is generally attributed to a loss of large motor neurones. ${ }^{10}{ }^{11}$ The clinical and electrophysiological findings may therefore be related to damage to the anterior horn of the cervicodorsal spinal cord (C7-T1), producing a loss of $\alpha$ motor neurones. Necropsy studies have confirmed structural changes in the anterior grey matter of the C6-Tl segments of the spinal cord. ${ }^{12}{ }^{13}$ However, there is still a very substantial measure of disagreement. Recently Hirayama has stated that "several authors in foreign countries did not or do not appreciate the pathologic findings of the disease, and still consider the illness a degenerative motor neuron disease." ${ }^{14}$

Generally speaking, Japanese investigators favour the hypothesis of a "traumatic chronic injury" leading to microvascular damage to the spinal cord during flexion-extension of the neck, which is particularly dangerous when growth is occurring rapidly in adolescents. ${ }^{15-18}$ An alternative hypothesis attributes the disorder to degenerative changes in the anterior horn of the spinal cord and therefore suggests that Hirayama's disease may be a benign focal variant among the forms of progressive spinal atrophy. ${ }^{19-21}$

Finally, high intensity signals in the lower anterior cervical cord have been observed in patients without evidence of flexion myelopathy, suggesting that pathological changes distinct from mechanical damage are present. ${ }^{22}$ To the best of our knowledge, only cortical somatosensory evoked potentials (SEP) have been recorded in Hirayama's disease patients. ${ }^{23}$ There is, therefore, a case for performing more extensive investigations of this type, so we conducted the study reported here in eight patients with this condition.

Responses to median nerve stimulation at the wrist appear to rely heavily on the $\mathrm{C} 6-\mathrm{C} 7$ roots; the additional use of ulnar nerve stimulation makes it possible to complete the assessment of the lower cervical roots, C8-T1. Isolated abnormalities of segmental N13-N22 spinal SEP (grey matter, postsynaptic potentials) have been observed in patients affected by cervical cord diseases presenting with muscle weakness and atrophy without any sensory disturbance, both at cervical level (syringomyelia, tumours) 24 $25^{25}$ and at lumbosacral level (chronic stretching in tethered cord syndrome). ${ }^{26}$ These are not potentials that are generated in the course of a volley ascending up through the medial lemniscus because, if that were the case, all the subsequent peaks should be abnormal. It would seem that a different system is being picked up, which probably breaks off at the spinal level.

The effects of spinal cord compression by stenosis or cervico-arthrosis primarily involve conduction in dorsal column fibres: greater sensitivity of gracile tract fibres to cervical cord compression has been proposed to explain isolated 
Table 1 Clinical findings in eight male cases of Hirayama's disease

\begin{tabular}{|c|c|c|c|c|c|c|c|c|}
\hline & Patient 1 & Patient 2 & Patient 3 & Patient 4 & Patient 5 & Patient 6 & Patient 7 & Patient 8 \\
\hline Age (years) & 59 & 68 & 26 & 33 & 45 & 23 & 21 & 25 \\
\hline Height $(\mathrm{cm})$ & 175 & 162 & 172 & 185 & 182 & 180 & 170 & 182 \\
\hline Onset age (years) & 18 & 25 & 17 & 18 & 19 & 17 & 17 & 18 \\
\hline Symptoms & $\begin{array}{l}\mathrm{R} \text { cold paresis, } \\
\text { weakness }\end{array}$ & $\begin{array}{l}\mathrm{L} \text { cold paresis, } \\
\text { weakness }\end{array}$ & $R$ weakness & $\begin{array}{l}\text { L weakness, } \\
\text { cold paresis }\end{array}$ & $\begin{array}{l}\mathrm{L} \text { cold paresis, } \\
\text { weakness }\end{array}$ & $\begin{array}{l}\mathrm{L} \text { cold paresis, } \\
\text { weakness }\end{array}$ & $\begin{array}{l}\text { L cold paresis, } \\
\text { weakness, } \\
\text { tremor }\end{array}$ & $\begin{array}{l}\text { R weakness, } \\
\text { tremor }\end{array}$ \\
\hline Progression & $R+L, 1$ year & $\begin{array}{l}\text { Biphasic: } \\
\text { L } 25 \text { months, } \\
\text { R } 42 \text { months }\end{array}$ & $\begin{array}{l}R \text { and } L \text {, } \\
2 \text { years }\end{array}$ & $\begin{array}{l}\text { Biphasic: } \\
\text { L } 18 \text { months, } \\
\text { R } 22 \text { months }\end{array}$ & $\begin{array}{l}\text { Biphasic: } \\
\text { L } 19 \text { months, } \\
\text { R } 22 \text { months }\end{array}$ & Monolateral & Monolateral & Monolateral \\
\hline Atrophy & $\mathrm{R}+++, \mathrm{L}++$ & $\mathrm{R}++, \mathrm{L}+++$ & $\mathrm{R}++, \mathrm{L}+$ & $\mathrm{R}+, \mathrm{L}++$ & $\mathrm{R}+, \mathrm{L}++$ & $\mathrm{L}+++$ & $\mathrm{L}++$ & $\mathrm{L}++$ \\
\hline $\begin{array}{l}\text { Tremor } \\
\text { Tendon reflexes }\end{array}$ & Yes & Yes & No & Yes & Yes & Yes & Yes & Yes \\
\hline Upper limbs & Brisk & Normal & Reduced $(R<L)$ & Reduced & Reduced & Reduced $(L<R)$ & Normal & Reduced $(L<R)$ \\
\hline Lower limbs & Brisk & Brisk & Normal & Normal & Normal & Normal & Normal & Normal \\
\hline
\end{tabular}

tibial nerve SEP abnormalities ${ }^{27}$; anterior damage to the cord interfering with the blood supply to the anterior spinal artery could produce associated abnormalities of the N13 response. ${ }^{28}$ Selective cortical SEP alterations have also been detected in patients with amyotrophic lateral sclerosis. ${ }^{29}$

In view of these findings, it is hard to refute the hypothesis that various SEP activities may reflect pathways both in series and in parallel: these activities should be studied simultaneously to obtain useful information. Transcranial and spinal magnetic stimulation contribute to the assessment of the motor pathways, and we used these techniques for additional evaluation of the corticospinal tract that lies on the border zone of the anterior spinal artery.

\section{METHODS \\ Patients}

We studied eight male patients, ranging in age from 17 to 67 years (mean 36.8), complaining of unilateral weakness and wasting of the hand and forearm muscles (the presenting symptoms were often difficulty in extending the wrist and fingers), eventually spreading to the contralateral upper extremity (table 1). Data from 10 normal male subjects were used for comparison.

\section{Diagnostic clinical criteria}

Criteria for diagnosis were as follows:

- Negative family history of neuromuscular disease;

- No CNS infection (for example, poliomyelitis);

- Onset in males between 15 and 30 years of age ( 17 to 25 in our cases);

- Insidious onset of unilateral or asymmetrical oblique amyotrophy; non-progressive course, arrest within a few years of onset;

- Postural tremors and cold paresis (table 1). Our patients complained at first, when obvious wasting was still absent, of upper limb weakness in the winter or when doing particular jobs (for example, while working in a cold store); later in the course of the disease, patients complained of a distinct worsening of the hand weakness in cold environments.

- Absence of pyramidal signs, diffuse fasciculations, sensory defects, cerebellar dysfunction, cranial nerve involvement, and sphincter disturbances.

\section{Conventional clinical electrophysiology}

The motor nerve conduction in the median, ulnar, and peroneal nerves and sensory conduction in the median, ulnar, and sural nerves were normal. The amplitudes of compound muscle action potentials following proximal and distal stimulation of the ulnar and median nerves showed no evidence of conduction block in any of the patients.

Needle electromyography (EMG) revealed mild spontaneous activity (fibrillation potentials, sharp waves) in clinically affected muscles - namely, the thenar, hypothenar, and interosseous muscles, the wrist flexors (mainly on the ulnar side) and extensors, and the triceps. Long duration, large amplitude (up to $10-15 \mathrm{mV}$ ) polyphasic potentials with a reduced recruitment pattern to single oscillations or greatly reduced to single motor units were observed. The extensor and ulnar flexors of the fingers and wrist were mostly involved; the brachioradialis muscle was spared in all cases.

\section{Laboratory investigations}

Spinal cord magnetic resonance imaging was done in all subjects with the neck in the normal position, with no pathological findings: no abnormal intrinsic cord signals were observed and the spinal cord was located normally within the cervical canal. Mild spondylotic compression of the dural sac was revealed in the sagittal view in three patients, and straightening of the physiological lordosis was found in five patients.

Blood samples excluded the presence of anti-GMl antibody and hexosaminidase deficiency. A superoxide dismutase 1 (SOD1) mutation was excluded in two patients.

\section{Neurophysiological measurements}

Median and ulnar SEP were obtained by stimulating the nerves at the wrist with electrical impulses capable of producing a muscle twitch of 2-2.5 times the sensory threshold whenever the muscle was severely hypotrophic. Square wave stimuli of $0.10 \mathrm{~ms}$ duration and $3 \mathrm{~Hz}$ frequency were used. Recordings were made from monopolar needle electrodes placed over the clavicle at the Erb point (EP) (frontal reference) and over the scalp in the contralateral frontal and parietal areas (contralateral ear lobe reference).

For the recording of the cervical N13 potential we connected the Cv6 (median nerve) or Cv7 (ulnar nerve) electrodes (over the sixth and seventh cervical spinous processes) to an electrode located immediately above the process of the thyroid cartilage (anterior cervical). The positive peak P9 was considered the onset of the triphasic N13 potential; the small negativity preceding the P9 was labelled N9 (fig 1A: median nerve SEP; fig 1B: ulnar nerve SEP).

Finally we measured the N9-P9 and P9-N13 peak to peak amplitudes. The latencies of EP, P9, P14, and N20 were measured. The electrode impedance was maintained at all times below 5 kohm. Sweep time was $100 \mathrm{~ms}$ and 500 responses were averaged for each trial.

The replicated trials were superimposed and measures were performed on the grand average. The high and low pass filter 
A

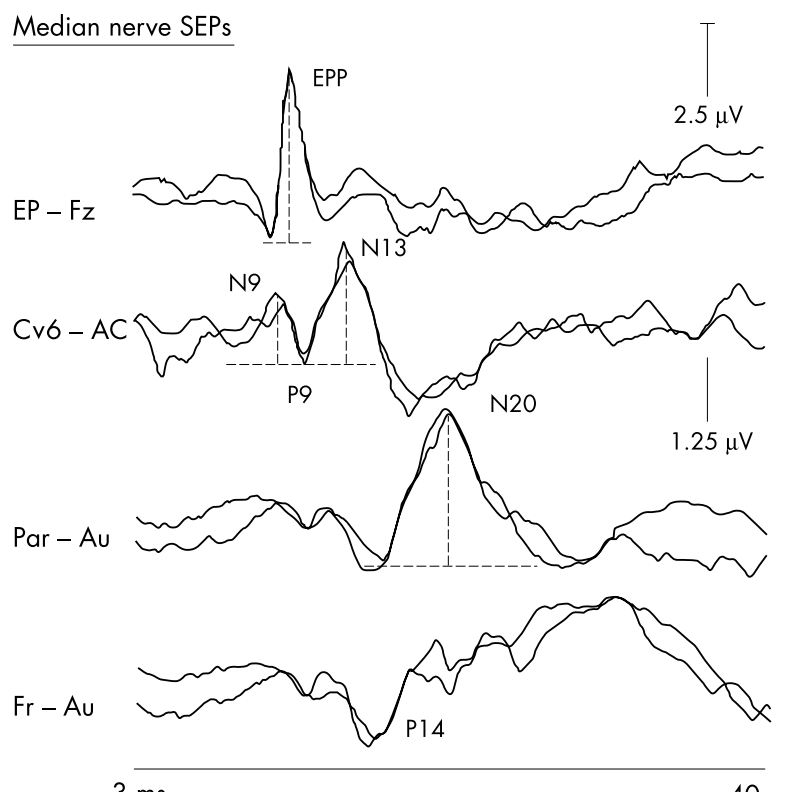

$3 \mathrm{~ms}$

$40 \mathrm{~ms}$

B

Ulnar nerve SEPs
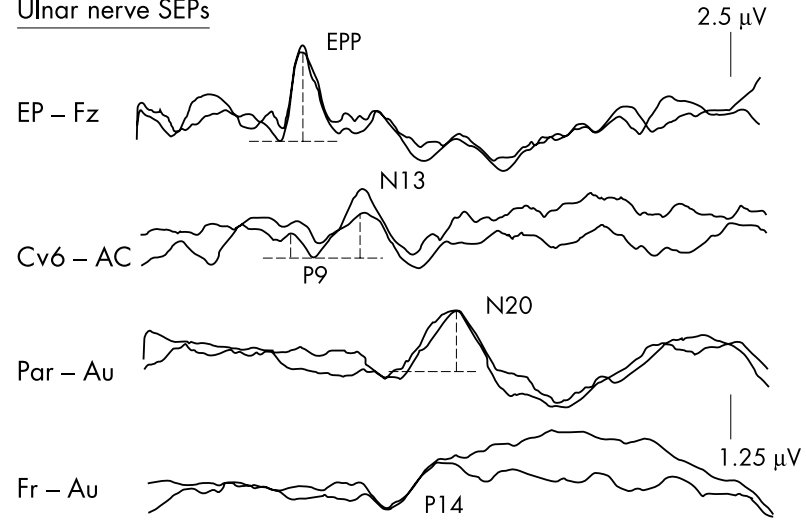

$3 \mathrm{~ms}$

$40 \mathrm{~ms}$

Figure 1 Normal tracings of median (A) and ulnar (B) somatosensory evoked potentials (SEP): individual peaks are labelled. Two consecutive recordings are shown; the final value represents the grand average. The sweep time is $3-40 \mathrm{~ms}$. AC, anterior cervical; $A u$, auricular lobe.

settings were 20-2000 $\mathrm{Hz}$ for the spinal and EP leads, and 5-1000 Hz for the scalp leads. Normal values (unpublished data) for both median and ulnar nerve SEP were obtained from a control group of 10 male subjects aged from 21 to 57 years (mean 35.7). Statistical analysis of the data for controls $v$ patients was done using Student's $t$ test, while side to side comparison was evaluated using Student's $t$ test.

The posterior tibial nerve was stimulated at the ankle with a suitable stimulus intensity in order to produce a muscle twitch; recordings were made by monopolar needle electrodes placed over the lumbar spinous processes L4 and L2 (reference) and over the scalp at the $\mathrm{Cz}, \mathrm{C} 3, \mathrm{C} 4$, and Fz leads using an ipsilateral (to the stimulated side) earlobe as reference.

Electroencephalographic (EEG) activity was amplified by setting the bandwidth at 5-2000 Hz, while spinal signals were processed with a $20-5000 \mathrm{~Hz}$ bandwidth. The averaged trace consisted of 500 artefact-free responses; normative data con- cerning the amplitude, latency, and scalp topography of the individual components have already been published.

The motor pathways were studied by recording the MEP elicited by a MagStim 200 (Magstim Co, Wales, UK) discharging rapidly into a circular copper coil (inner diameter $9 \mathrm{~cm}$ ). This was placed on the skull vertex and over the spinous processes of C7 (upper limbs) and L3 (lower limbs). EMG responses were recorded from the tibialis anterior and thenar muscles on both sides and were represented by the MEP at rest occurring with an output intensity about $20-30 \%$ above the motor threshold. Both peripheral and central conduction times were calculated.

\section{RESULTS}

Median and ulnar SEP latencies

There was no significant difference in peripheral conduction time, calculated as the mean latency of the EP potential, between patients and controls. The P9-P14 interpeak time was measured in order to evaluate dorsal column system conduction and the P14-N20 interval was measured to assess the function of the lemniscal pathway and the thalamocortical input: no differences in values were found between controls and patients. The mean values and standard deviations are presented in table 2 .

\section{Median nerve SEP amplitudes}

The mean amplitude of the EP potentials was much lower in the patients than in the control subjects (mean (SD): 3.41 (1.57) $v 6.21(1.45) \mu \mathrm{V} ; \mathrm{p}=0.0002)$. The mean amplitude of the far field potential P9 was lower in the patients than in the controls $(0.64(0.23) \vee 1.05(0.26) \mu \mathrm{V} ; \mathrm{p}=0.01)$. The mean amplitude of the segmental N13 potential was much lower in patients than in the controls $(0.96(0.52) v 1.97(0.42) \mu \mathrm{V}$; $\mathrm{p}=0.00007)$.

The mean amplitude values of both the N18 and N20 scalp potentials were found to be similar in patients and normal controls, with no statistically significant difference.

As three patients had strictly unilateral clinical involvement, we observed that among the 13 median nerves examined in the affected extremities, the EP amplitude was below 2.5 SD in $72 \%(9 / 13)$ while the N13 amplitude was below $2.5 \mathrm{SD}$ in $80 \%(10 / 13)$. The traces from one patient are illustrated in fig 2 .

\section{Ulnar nerve SEP amplitudes}

The EP potential had a smaller mean amplitude in the patients than in the controls $(1.39(0.62) v 2.67(0.58) \mu \mathrm{V} ; \mathrm{p}=0.0004)$. The mean amplitude of the far field potential P9 was lower in patients than in the controls $(0.36(0.12) \vee 0.57(0.11) \mu \mathrm{V}$; $\mathrm{p}=0.04)$. The mean amplitude of the segmental N13 was much lower in patients than in the controls $(0.72(0.28) v 1.21$ (0.19) $\mu \mathrm{V} ; \mathrm{p}=0.0009$ ).

The mean amplitude values of both the N18 and N20 scalp potentials were similar in patients and controls, with no statistically significant differences.

As three patients had strictly unilateral clinical involvement, we observed that among the 13 median nerves examined in the affected extremities, the EP amplitude was below 2.5 SD in $42 \%(6 / 13)$ while the N13 amplitude was below 2.5 SD in $66 \%(9 / 13)$. The traces from one patient are illustrated in fig 3.

\section{Posterior tibial nerve SEP}

Peripheral conduction time was normal in the patients with Hirayama's disease. Both the latency and the amplitude of the spinal P22 (bipolar L4-L2) recording were within normal limits. The central conduction time (P22-P37/N37) was also normal. The paradoxical lateralisation of the early latency scalp potentials (N37-P37) was correctly evoked in all but two patients (Nos 1 and 2), in whom the pattern of scalp SEP was 


\begin{tabular}{|c|c|c|c|c|}
\hline & & $\mathrm{HD}($ mean $(\mathrm{SD}))$ & Controls (mean (SD)) & $t$ Test (p) \\
\hline \multicolumn{5}{|l|}{ LATENCY (ms) } \\
\hline \multirow[t]{7}{*}{ Median nerve SEP } & EPP & $10.23(0.59)$ & $10.15(0.34)$ & $>0.05$ \\
\hline & PQ & $10.69(0.66)$ & $10.52(0.62)$ & $>0.05$ \\
\hline & $\mathrm{N} 13$ & $13.49(0.76)$ & $13.48(0.45)$ & $>0.05$ \\
\hline & $\mathrm{P} 14$ & $14.76(0.62)$ & $14.75(0.46)$ & $>0.05$ \\
\hline & N2O & $19.81(0.75)$ & $19.36(0.61)$ & $>0.05$ \\
\hline & P9-P14 & $4.54(0.16)$ & $4.27(0.15)$ & $>0.05$ \\
\hline & P14-N20 & $5.04(0.18)$ & $4.61(0.13)$ & $>0.05$ \\
\hline \multirow[t]{7}{*}{ Ulnar nerve SEP } & EPP & $10.89(0.61)$ & $10.59(0.58)$ & $>0.05$ \\
\hline & PQ & $11.12(0.68)$ & $11.09(0.75)$ & $>0.05$ \\
\hline & $\mathrm{N} 13$ & $14.35(0.69)$ & $13.98(0.65)$ & $>0.05$ \\
\hline & P14 & $15.61(0.73)$ & $15.33(0.71)$ & $>0.05$ \\
\hline & N20 & $20.57(0.72)$ & $19.98(0.64)$ & $>0.05$ \\
\hline & P9-P14 & $4.47(0.21)$ & $4.22(0.19)$ & $>0.05$ \\
\hline & P14-N20 & $4.92(0.23)$ & $4.65(0.21)$ & $>0.05$ \\
\hline \multicolumn{5}{|l|}{ AMPLITUDE $(\mu \mathrm{V})$} \\
\hline \multirow[t]{4}{*}{ Median nerve SEP } & EPP & 3.41 (1.57) & $6.21(1.45)$ & 0.0002 \\
\hline & PQ & $0.64(0.23)$ & $1.05(0.26)$ & 0.01 \\
\hline & $\mathrm{N} 13$ & $0.96(0.52)$ & $1.97(0.42)$ & 0.00007 \\
\hline & N2O & $2.43(0.72)$ & $2.85(0.62)$ & $>0.05$ \\
\hline \multirow[t]{4}{*}{ Ulnar nerve SEP } & EPP & $1.39(0.62)$ & $2.67(0.58)$ & 0.0004 \\
\hline & PQ & $0.36(0.12)$ & $0.57(0.11)$ & 0.04 \\
\hline & $\mathrm{N} 13$ & $0.72(0.28)$ & $1.21(0.19$ & 0.0009 \\
\hline & N2O & $1.72(0.54)$ & $1.83(0.34)$ & $>0.05$ \\
\hline
\end{tabular}

predominantly represented by the contralateral N37 potential, the ipsilateral P37 potential being largely attenuated.

\section{Side to side comparison}

The degree of SEP abnormalities correlated poorly with the degree of clinical abnormality-statistical significance was not achieved $(p>0.05)$ on comparing the values of individual SEP obtained from the better sides with those obtained from the worse sides of the patients.

\section{Magnetic stimulation}

The mean latency of cervical MEP from the thenar eminence was slightly longer in the patients than in the controls (14.08 (0.83) $v 12.74(0.81) \mathrm{ms} ; \mathrm{p}=0.02)$. The central conduction time was also slightly slower in the patients than in the controls $(9.32(0.63) v 8.51(0.59) \mathrm{ms} ; \mathrm{p}=0.01)$.

As stimulation of the cervical area with the coil over the C7-Tl spinous processes excites the motor roots at the foramina at the point where they depart from the spinal canal, ${ }^{30}$ the conduction time-calculated as the difference in latency between the scalp MEP and the cervical MEPtherefore contains a small peripheral component. For this reason, we considered the variable loss of $\alpha$ motor neurones (large diameter axons) as being responsible for the slight delay in conduction along the motor pathways.

The mean latency of lumbar MEP from tibial muscle was 14.13 (1.65) $\mathrm{ms}$; the central conduction time ( $\Delta$ scalp MEP - lumbar MEP) was 16.23 (1.38) ms. No statistical difference was found between patients and controls.

\section{DISCUSSION}

Our patients with Hirayama's disease had muscle wasting in the hands and forearms (predominantly C7-Tl segmental involvement) without any sensory defect of the corresponding dermatome. Hyporeflexia was generally found in the upper

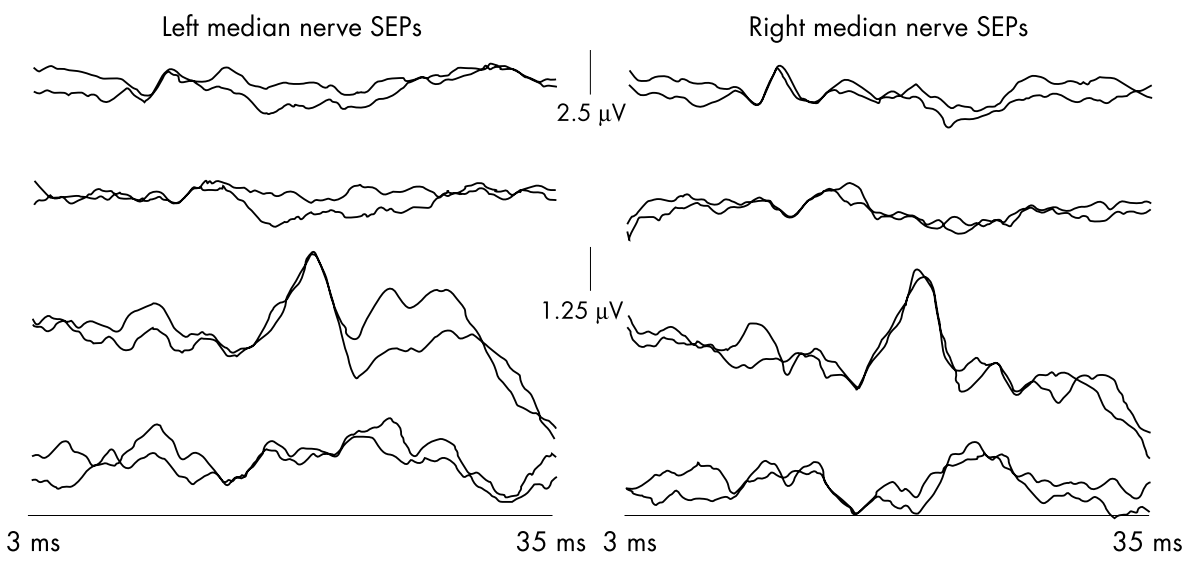

Figure 2 Median nerve somatosensory evoked potentials (SEP) in patient 2, showing an asymmetrical involvement (the atrophy was more pronounced on the left). The amplitude reduction of both Erb's point (EP) and N13 potentials is more pronounced after left sided than after right sided stimulation. The $\mathrm{N} 20$ amplitude is symmetrically normal. The sweep time is $3-35 \mathrm{~ms}$. 

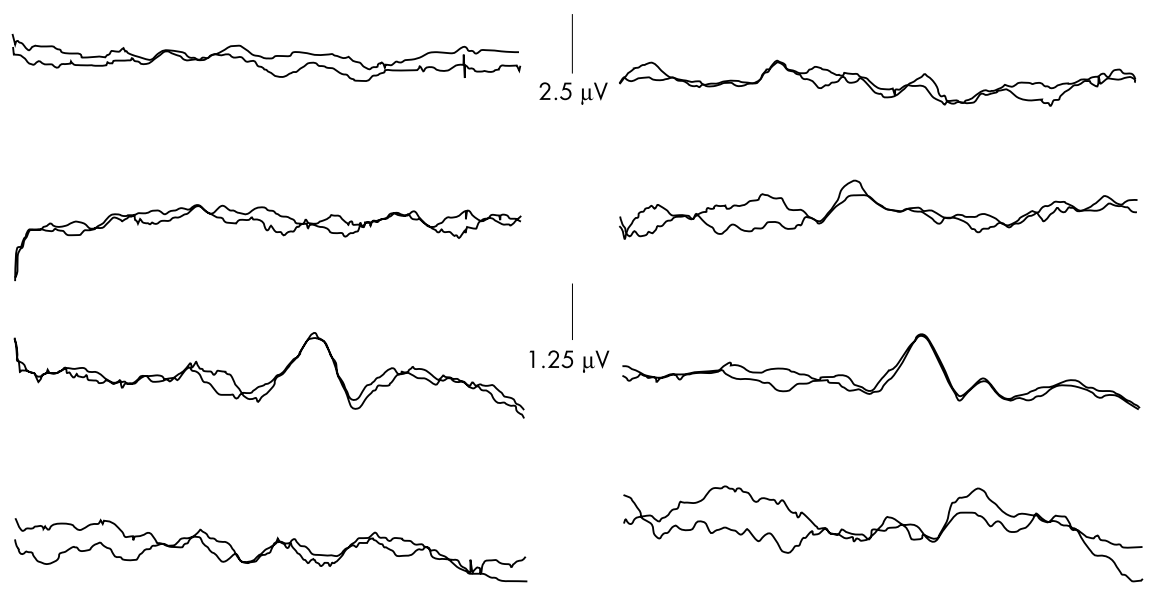

$3 \mathrm{~ms}$

$35 \mathrm{~ms}$

$3 \mathrm{~ms}$

$35 \mathrm{~ms}$

Figure 3 Ulnar nerve somatosensory evoked potentials (SEP) in the same patient as in fig 2. The amplitude reduction of both Erb's point (EP) and N13 potentials is more pronounced after left sided than after right sided stimulation. The N20 amplitude is symmetrically normal. The sweep time is $3-35 \mathrm{~ms}$.

limbs. Clinical and EMG patterns were suggestive of chronic anterior horn neurone damage.

Dissociated abnormalities were found on examination of upper limb SEP: the EP potential and the cervical N13 response were significantly smaller in patients than in controls, while the subcortical and cortical components were normal in amplitude; the conduction times, both peripheral and central, were also within normal limits. These findings were observed following stimulation of the median and ulnar nerves. We also compared the results obtained from the affected (worse) sides with those obtained from the unaffected or less affected (better) sides, but the paired $t$ test revealed no statistical significance.

The EP is a bi-triphasic potential corresponding to the brachial plexus travelling wave produced by motor and sensory nerve fibres. The maximum amplitude can be obtained by stimulating a mixed nerve at about twice the sensory threshold. This condition predominantly initiates a relatively synchronous volley, spreading along the large diameter fast conducting group Ia muscle and group II cutaneous afferent fibres. ${ }^{31}$ The amplitude contribution of the motor fibres to the EP waveform varies in relation to the stimulus intensity, being $30 \%$ at supramaximal stimulation and $10-20 \%$ when using a stimulus only slightly above the motor threshold. ${ }^{32} 33$ The stimulation of a cutaneous nerve evokes an EP potential of smaller amplitude than the stimulation of a mixed nerve can evoke; there is, however, no difference in the conduction times of the fastest cutaneous fibres and the fastest fibres in the mixed nerve action potential. ${ }^{34}$ At the same time, the degree of contamination of the peak latency of the mixed nerve action potential resulting from the antidromic activation of major efferent fibres is negligible. Cutaneous afferent fibres can be regarded as being functionally unaffected in our patients. In fact, the patients had normal sensory perception (touch, temperature, pain) and their sensory nerve action potentials displayed an appropriate amplitude. Vibration sense and proprioception (kinaesthesia) were also spared. As these systems, tested by clinical methods, were apparently functioning, we suggest that the amplitude reduction of the EP potential might correlate with subclinical symptoms. Whether the afferent fibres are only functionally involved (loss of excitability) or structurally damaged (by a degenerative process) by an injury is largely a matter for speculation. To a lesser extent, the loss of motor axons can be added to the loss of afferent fibres in order to better explain the limited amplitude of the brachial plexus potential. The resulting effect, however, may be a minor contribution to the nerve action potential (EP) following stimulation of a mixed peripheral nerve.

Surface cervical recordings detect a widespread neck potential N13. Using surface $\mathrm{C} 7$ anterior neck recording, the "caudal" N13 wave is maximal posteriorly above the spinal processes of $\mathrm{C} 6-7$, corresponding to the entry zone of the lower cervical roots. It represents the negativity of a dipole (N13-P13) with an anterior-posterior direction, reversing the phase with a null part over the lateral neck. ${ }^{35}{ }^{36}$ The existence of a "rostral" N13 has led to the hypothesis that there are parallel pathways in the SEP source arrangement. ${ }^{37}$

In our patients, an important finding was the conspicuous reduction in the N13 amplitude following both median and ulnar nerve stimulation. We also found that the SEP did not show any conduction involvement along the dorsal column fibres and lemniscal pathways (P9, P14, and N20 latencies were normal), and the amplitude of the cortical response was no different between Hirayama's disease and controls. These segmental SEP abnormalities reflect a reduced response at the cervical level.

An isolated loss of the N13 potential has been reported in syringomyelia, ${ }^{24}$, cord tumours, ${ }^{25}$ and cervical spondylosis with anterior spinal artery involvement. ${ }^{28}$ These electrophysiological alterations have not been consistently found to be associated with a sensory perception defect (possibly pain and temperature). Direct recordings have shown one or more intramedullary potentials that reverse the phase between the dorsal and ventral grey matter. ${ }^{38}$ The inputs are conveyed by group I-II afferent fibres through the dorsal root to the dorsal horn and through interneurones further on to motor neurones in the anterior horn; these neural activities are thought to contribute to the generation of the N13 wave. As with the EP amplitude reduction, the occurrence of N13 changes could reflect subclinical sensory fibre involvement and motor neurone loss.

All patients had normal central conduction time along the sensory pathways from the lower limbs. Isolated cortical SEP abnormalities produced by marked attenuation of the ipsilateral P37 made paradoxical lateralisation ${ }^{39}$ uncertain; these abnormalities were found in patients 1 and 2, who had brisk tendon reflexes in the lower limbs and longstanding disease (more than 30 years). Hypereflexia is unusual in Hirayama's 
disease, but the absence of plantar extension signs and, in agreement with previous studies, ${ }^{40}$ the normal magnetic stimulation results are not suggestive of pyramidal tract dysfunction.

\section{Conclusions}

Different abnormalities affect SEP on stimulation of the median and ulnar nerves in Hirayama's disease, as the amplitudes of the EP and N13 potentials are greatly reduced. The conduction times along the posterior columns, medial lemniscus, and pyramidal pathways are normal, providing evidence that the long tracts are spared in this particular cervical myelopathy. In the opinions of most investigators, mechanical injury causes focal anterior horn cell damage and loss, often producing an asymmetrical upper limb muscle involvement. The disorder might also involve the sensory fibres during chronic trauma-overstretching of the cord ${ }^{15}$ or disproportionate shortening of the dorsal root $^{16}$ have been shown during dynamic changes in the spinal canal. It is therefore likely that sensory cells and fibres generating the EP and perhaps even the N13 may consequently be injured as the cord and the roots are stretched, though not enough to affect the amplitude of the cortical N20.

Though not conclusive, the SEP results in our patients with Hirayama's disease provide electrophysiological evidence of particular damage to the nervous system. Interestingly, the SEP abnormalities are not related to the clinical motor involvement. We can only speculate that if an injury mechanism exists, the damage is not simply confined to the anterior horn of the spinal cervical cord but also involves peripheral nerve structures.

\section{ACKNOWLEDGEMENTS}

We wish to thank Dr Ettore Nardelli for his help with the laboratory investigation and Professor Anthony Steele for his linguistic assistance in editing the text.

\section{Authors' affiliations}

A Polo, Department of Neurology, City Hospital, Padova, Italy M Curro' Dossi, A Fiaschi, G P Zanette, N Rizzuto, Department of Neurological and Visual Sciences, Section of Neurology, University of Verona, Verona, Italy

Competing interests: none declared

\section{REFERENCES}

1 Hirayama K, Tsubaki T, Tokoyura Y. Juvenile muscular atrophy of unilateral upper extremity - a new clinical entity. Psychiatr Neurol Jpn 1959;61:2190-7.

2 Sobue I, Saito N, lida $M$, et al. Juvenile type of distal and segmental muscular atrophy of upper extremities. Ann Neurol 1978;3:429-32.

3 Singh N, Sachdev KK, Susheela AK. Juvenile muscular atrophy localized to arm. Arch Neurol 1980;37:297-9.

4 Virmani V, Mohan PK. Non-familial spinal segmental muscular atrophy in juvenile and young subjects. Acta Neurol Scand 1985;72:336-40.

5 Peiris JB, Seneviratne HN, Wickremasinghe HR, et al. Non-familial juvenile distal spinal muscular atrophy of upper extremity. J Neurol Neurosurg Psychiatry 1989;52:314-19.

6 Chen CJ, Chen CM, Wu CL, et al. Hirayama disease: MR diagnosis. Am J Neuroradiol 1998;19:365-8

7 Harding AE, Bradbury PG, My NMF. Chronic asymmetrical spinal muscular atrophy. J Neurol Sci 1983;59:69-83.

8 Gouri-Devi M, Suresh TG, Shankar SK. Monomelic amyotrophy. Arch Neurol 1984;41:388-94

9 Chan YM, Kay R, Schwartz MS. Juvenile distal spinal muscular atrophy of upper extremities in Chinese males: a single fibre electromyographic study of arms and legs. J Neurol Neurosurg Psychiatry 1991;54:165-6.

10 Tandan R, Sharma KR, Bradley WG, et al. Chronic segmental spinal muscular atrophy of upper extremities in identical twins. Neurology 1990;40:236-9

11 Donofrio PD. Monomelic amyotrophy. Muscle Nerve 1994;17:1129-34.
12 Swash $M$, Leader $M$, Brown A, et al. Focal loss of anterior horn cells in the cervical cord in motor neuron disease. Brain 1986;109:939-52.

13 Araki K. An autopsy case of juvenile muscular atrophy of unilateral upper extremity. J Jpn Soc Intern Med 1989;78:674-5.

14 Hirayama K. Juvenile muscular atrophy of distal upper extremity (Hirayama disease): focal cervical ischemic poliomyelopathy. Neuropathology 2000;20:91-4.

15 Hashimoto O, Asada $M$, Ohta $M$, et al. Clinical observations of juvenile non-progressive muscular atrophy localized in hand and forearm: original investigations. J Neurol 1976;211:105-10.

16 Kikuchi S, Tashiro K, Kitagawa M, et al. A mechanism of juvenile muscular atrophy localized in the hand and forearm (Hirayama's disease) - flexion myelopathy with tight dural canal in flexion. Clin Neurol 1987;27:412-19.

17 Toma S, Shiozawa Z. Amyotrophic cervical myelopathy in adolescence. J Neurol Neurosurg Psychiatry 1995;58:56-64.

18 Hirayama K, Tokumaru Y. Cervical dural sac and spinal cord in juvenile muscular atrophy of distal upper extremity. Neurology 2000;54:1922-6.

19 Adornato BT, Engel K, Kucera J, et al. Benign focal amyotrophy. Neurology 1978;28:399.

20 Chaine $\mathbf{P}$, Bouche $\mathrm{P}$, Leger JM, et al. Atrophie musculaire progressive localisée a la main. Forme monomélique de la maladie du motoneuron? Rev Neurol 1988; 144:759-63.

21 Schroeder R, Keller E, Flacke S, et al. MRI findings in Hirayama's disease: flexion-induced cervical myelopathy or intrinsic motor neuron disease? J Neurol 1999:246:1069-74.

22 Willeit J, Kiechl S, Kiechl-Kohlendorfer U, et al. Juvenile asymmetric segmental spinal atrophy (Hirayama disease). Three cases without evidence of "flexion myelopathy". Acta Neurol Scand 2001;104:320-2.

23 Pradhan S, Gupta RK. Magnetic resonance imaging in juvenile asymmetric segmental spinal muscular atrophy. J Neurol Sci 1997; 146:133-8.

24 Restuccia D, Mauguiere F. The contribution of median nerve SEPs in the functional assessment of the cervical spinal cord in syringomyelia. A study of 24 patients. Brain 1991;114:361-79.

25 Ibanez V, Fischer G, Mauguiere F. Dorsal horn and dorsal column dysfunction in intramedullary cervical cord tumours. A somatosensory evoked potential study. Brain 1992;115:1209-34.

26 Polo A, Zanette G, Bertolasi L, et al. Spinal somatosensory evoked potentials in patients with tethered cord syndrome. Can J Neurol Sci 1994;21:325-30.

27 Yu YL, Jones SJ. Somatosensory evoked potentials in cervical spondylosis: correlation of median, ulnar and posterior tibial nerve responses with clinical and radiological findings. Brain 1985; 108:273-300.

28 Restuccia D, di Lazzaro V, Valeriani $M$, et al. Segmental dysfunction of the cervical spinal cord revealed by abnormalities of the spinal N13 potential in cervical spondylotic myelopathy. Neurology 1992;42: 1054-63

29 Zanette G, Tinazzi M, Polo A, et al. Motor neuron disease with pyramidal tract dysfunction involves the cortical generators of the early somatosensory evoked potentials to tibial nerve stimulation. Neurology 1996;47:932-8.

30 Britton TC, Meyer BU, Herdman J, et al. Clinical use of the magnetic stimulator in the investigation of peripheral conduction time. Muscle Nerve 1990;13:396-406.

31 Halonen JP, Jones S, Shawkat F. Contribution of cutaneous and muscle afferent fibers to cortical SEPs following median and radial nerve stimulation in man. Electroencephalogr Clin Neurophysiol 1988;71:331-5.

32 Chiappa KH. Short-latency somatosensory evoked potentials: methodology. In: Chiappa KH, ed. Evoked potentials in clinical medicine, 3rd ed. Philadelphia: Lippincott-Raven, 1997:283-339.

33 Aminoff MJ, Eisen AA. Somatosensory evoked potentials. Muscle Nerve 1998;21:277-90

34 Gandevia SC, Burke D, McKeon BB. The projection of muscle afferents from hand to cerebral cortex in man. Brain 1984;107:1-13.

35 Emerson RG, Seyal M, Pedley TA. Somatosensory evoked potentials following median nerve stimulation. 1. The cervical components. Brain 1984;107:169-82.

36 Zanette G, Tinazzi M, Manganotti $P$, et al. Two distinct cervical N13 potentials are evoked by ulnar nerve stimulation. Electroencephalogr Clin Neurophysiol 1995;96:114-20.

37 Desmedt JE, Cheron G. Prevertebral (oesophageal) recording of subcortical somatosensory potentials in man: the spinal P13 component and the dual nature of the spinal generators. Electroencephalogr Clin Neurophysiol 1981:52:257-75.

38 Jeanmonod D, Sindou M, Mauguiere F. The human cervical and lumbo-sacral evoked electrospinogram. Data from intra-operative spinal cord surface recordings. Electroencephalogr Clin Neurophysiol 1991:80:477-89.

39 Lesser RP, Lueders H, Dinner DS, et al. The source of paradoxical lateralization of cortical evoked potentials to posterior tibial nerve stimulation. Neurology 1987;37:82-8.

40 Misra UK, Kalita J. Central motor conduction in Hirayama disease. Electroencephalogr Clin Neurophysiol 1995;97:73-6. 